Article

\title{
Towards Improved Energy and Resource Management in Manufacturing
}

\author{
Sanober Hassan Khattak ${ }^{1, *(1)}$, Michael Oates ${ }^{2}$ and Rick Greenough ${ }^{3}$ (10) \\ School of Mechanical, Aerospace and Automotive Engineering, Coventry University, Coventry CV1 5FB, UK \\ 2 Integrated Environmental Solutions Limited, Helix Buildings, West of Scotland Science Park, \\ Glasgow G20 0SP, UK; mike.oates@iesve.com \\ 3 Institute of Energy and Sustainable Development (IESD), De Montfort University, Queens Building, \\ The Gateway, Leicester LE19BH, UK; rgreenough@dmu.ac.uk \\ * Correspondence: ac7397@coventry.ac.uk or san.uni@hotmail.com
}

Received: 15 March 2018; Accepted: 9 April 2018; Published: 20 April 2018

\begin{abstract}
Exergy analysis has widely been used to assess resource consumption, and to identify opportunities for improvement within manufacturing. The main advantages of this method are its ability to account for energy quality and consumption. However, its application in industrial practice is limited, which may be due to the lack of its consistent application in practice. Current energy management standard, that facilitate consistent application of procedures do not consider the quality aspects of energy flows. An exergy based energy management standards is proposed in this paper that would take into account energy quality aspects, while facilitating the consistent application of exergy analysis in industrial practice. Building on ISO50001, this paper presents guidelines for implementing energy and resource management in factories, incorporating the concepts of exergy and holistic factory simulation, as illustrated through a manufacturing case study. From the factory level analysis, a chilling process was identified to have significant improvement potential. A dry fan cooler, using ambient air was proposed for the improved efficiency of the chillers. Energy based metrics portrayed a system that operated at high efficiency, however exergy analysis indicated much room for further improvement, therefore impacting decision making for technology selection. The contribution of this paper is in presenting a set of prescriptive guidelines that could possibly be further developed into a new energy management standard that would utilize the advantages of exergy analysis towards improved energy and resource management in manufacturing.
\end{abstract}

Keywords: energy management; industrial energy efficiency; resource efficient manufacturing; exergy analysis; energy management standards

\section{Introduction}

According to the U.S. Energy Information Administration (EIA), industry was responsible for more than half (54\%) of the worldwide energy consumption in 2016 [1]. Furthermore, the industrial sector's energy use is expected to grow by $1.2 \%$ yearly up to 2040 [1]. There is a limited availability of energy, material, and clean water resources that support human activity on planet Earth. Since industry is a major consumer of natural resources, global efforts are directed to reduce industrial energy and resource consumption. For example, the European Union designated resource efficiency as one of the seven flagship initiatives in its Europe 2020 strategy for smart, sustainable, and inclusive growth [2]. Approaches and policies for resource efficiency of 31 countries were surveyed and summarized in [3]. In a similar report for the UK, Dawkins, Roelich [4] outlined broad measures for improved resource efficiency in the UK. Therefore, this topic is of worldwide importance, and it is the subject of this article. 
In this paper, a methodology is presented that could possibly lead to improved energy and resource management in manufacturing. Sections 1.1 and 1.2 provide a background to approaches for resource accounting in manufacturing and energy management standards, which leads to the specification of the research objective in Section 1.3. Section 2 is about the research methodology employed in this work. Section 3 presents the exergy based energy management methodology, as proposed in this paper, which is illustrated through implementation on a manufacturing case study (Section 4).

\subsection{Approaches to Resource Accounting for Manufacturing}

Manufacturing systems are complex entities with multiple subsystems that are interacting dynamically. With a variety of products in manufacturing, variations in their production design, and continuous development in technology, different methodologies and tools have been developed to assess them. Various theoretical paradigms, modelling techniques, and simulation approaches are present to address the needs of sustainable manufacturing. State of the art literature in this area is increasingly focused on viewing the factory as a whole system. The factory is considered to be comprised of the factory building, production processes, and building services, interacting dynamically with each other $[5,6]$. The primary reasons for this inclination are as follows;

1. Many production processes require inputs from building services, thus resulting in an interdependent relationship between the two. Analyzing one while ignoring the other may therefore lead to misleading results.

2. Often, the use of energy, material, and water is interdependent, where the consumption or conservation of one can affect the other. Thus, a holistic approach prevents problem shifting, which may arise from isolated analysis of the factory sub-components.

3. A holistic analysis of the factory resource flows allows identifying greater opportunities for resource recovery.

Ball et al. [7] proposed a conceptual model that was based on this holistic view of the factory, to be implemented through computer software. Duflou et al. [8] reviewed the methods and techniques for improving energy and resource efficiency in discreet parts manufacturing. The review article highlighted the importance of using building physics principles is resource efficiency analysis at the factory level, primarily to minimize the energy requirements of the heating, ventilation and air-conditioning (HVAC) for the factory working environment.

This paradigm shift from conventional approaches towards a need to assess factories as holistic systems, with added consideration for the building services in addition to the production processes was recorded by Herrmann et al. [9]. A need for the factories of the future to be adaptive and be able to develop symbiotic integration with its surroundings was highlighted. An important aspect in such conceptual models is the reuse of resources through the 'closed loop' concept which is an idealized optimum sustainable solution [10]. Attempts have been made to implement this concept in practice through tools development. For example, Kovacic et al. [11] implemented an integrated simulation of an industrial facility that housed machining processes, with a heavy focus on the building's modelling and heat gains due to the production line. Caggiano et al. [12] developed a multi-purpose simulation approach that utilized discreet event simulation (DES) and applied to a fabrication facility for aircraft parts manufacturing. Garwood et al. [13] reviewed the advances in holistic factory simulation, from the inception of the idea, to the latest software capable of delivering the concept practically. Due to the challenges of modelling and simulation across the different levels of the manufacturing facility, whilst taking into account the interdependencies, the authors concluded that progress on this front is still in its early stages, and further development is required towards a comprehensive simulator.

It is clear that a holistic approach to the analysis of manufacturing systems is beneficial for energy and resource management. However, predominantly, studies from literature are either based on energy 
analysis, or material analysis that may not allow for identifying the full range of opportunities [14]. Hernandez and Cullen [15] analyzed a Blast furnace, for which improvement options were identified based on (i) an energy analysis; (ii) material efficiency analysis; and, (iii) exergy analysis. The results showed that the greatest opportunities were identified by considering both material and energy on a common unit basis, using exergy.

A truly holistic approach to analysis of manufacturing systems, in addition to considering the factory building resource consumption, should allow concurrent comparison of improvement options that may involve material or water flows in addition to energy. For this reason, some researchers have attempted the modelling of flows in this manner to identify greater resource reuse opportunities. Mousavi et al. [16] presented a hierarchal framework for the simultaneous consideration of water flows alongside energy in manufacturing facilities. Thiede et al. [17] proposed a 'multi-level' simulation approach which again catered to the interdependency between energy and water. An exergy based approach to modelling of resource flows within the manufacturing context was presented by Khattak et al. [18,19], to allow for the concurrent assessment of improvement options that may involve energy, material or water.

Studies based on mass and energy balances exclude any notion of resource consumption since we know that mass and energy are conserved quantities. Additionally, energy flows are not completely defined by their quantity alone, as their quality is equally important Khattak et al. [20]. Therefore, the application of exergy analysis may therefore lead to clearer information about resource consumption improvement options in the factory environment. For this reason, exergy analysis is a mature concept in the field of environmental science and has been applied to a range of industrial systems. For examples, see Wall [21] (a paper mill and a steel plant), Atmaca and Yumrutas [22] (a cement plant) and McKenna [23] (glass manufacturing). Many other such examples are present in the literature, from which it is clear that exergy analysis is gaining increased importance in the field of industrial energy management and resource efficiency.

With these advantages of exergy analysis and acceptance in academia, one would expect it to be the tool of choice when making energy and resource efficiency assessments in industrial practice. However, this is not the case in reality. There are inconsistencies in the theoretical formulation of the exergy concept [24], but this has not been recorded as the main reason for its non-penetrance in industrial energy management. According to Rosen [25], unfamiliarity of the exergy concept in the industry, and viewing the analysis method as too cumbersome and complicated are among the main reasons that impede its application in practice. The results of a survey on this topic revealed similar results [26]. There are also limitations in the exergy concept with regards to the selection of the reference environment [27]. Nonetheless, owing to its advantages, it has potential in delivering improved energy and resource management in comparison to methods based on the first law of thermodynamics [28]. As such, it has been identified as a useful tool that can provide clearer information about energy efficiency opportunities, thus addressing a barrier to improved industrial energy management [29]. The following sections provide information on how this useful tool can be put into greater practice.

\subsection{Energy Management Standards}

As discussed in Section 1.1, exergy analysis can be a powerful tool for industrial resource accounting and may lead to improved energy management in comparison with energy analysis based techniques alone. However, its use is impeded by the lack of acceptance by industry and its consistent application in practice. Perhaps encapsulating the concept of exergy in energy management standards can help in tackling these barriers to improved energy management. Energy management standards allow organizations to achieve and maintain energy efficiency in their processes. In doing so, the energy auditing, analysis and monitoring processes are consistently applied. A number of such standards were developed in the first decade of the 21st century, originating from a range of different countries [30]. Notable among them were the EN 16001:2009 and ANSI/MSE 2000:2008. The ANSI/MSE 2000:2008 was developed in the United States and specified the requirements for 
Management systems for Energy (MSE) [31]. The objective of the standard was to guide organizations to reduce the non-renewable resource consumption and costs by addressing the life cycle aspects of energy resources. The EN 1600:2009, which was developed by the British Standards Institute (BSI), was another standard, with similar objectives, but with more focus on continual improvement. National standard bodies such as the BSI and ANSI are now members of the ISO (International organization for standardization), and the latest energy management standard, the ISO 50001 has essentially succeeded previous standards, such as the EN 16001:2009 [32].

The ISO 50001 is based on the Plan-Do-Check-Act (PDCA) framework for continual improvement. As evident from the name, the PDCA is comprised of four phases, (i) Planning energy management activities; (ii) Implementing improvement measures; (iii) Monitoring the performance of the improvement measures; and, (iv) Correction and scoping for further improvement. Through the implementation of the PDCA, ISO 50001 requires an organization to develop and implement an energy policy, identify significant areas of energy usage, followed by continual improvement. The energy policy, energy targets and objectives, together with the implementation of the step-by-step prescriptive approach leads to an energy management system (EnMS). The ISO 50001 has been widely applied by organizations around the world as a total of 1,644,357 certifications had been awarded by 2016 [33]. Since it is a generic energy management methodology, it has been applied outside of manufacturing [32], however its main application has been for industrial energy management. For example, Fabrizio et al. [34] surveyed the state of energy management penetration in the Italian industry, and found that 35\% of companies were ISO 50001 certified indicating a need for further improvement. Gopalakrishnan [35] developed an energy analyzer software to facilitate the application and the certification of ISO 50001 in industrial facilities. Other such examples of implementing industrial energy management and standards can readily be found in literature [36-38]. May et al. [28] reviewed literature from 1995 to 2015, and identified four key aspects of energy management for manufacturing, one of which are the tools and methods that support energy management, see Figure 1. As Section 1.1 provided a review of such modelling and analysis methodologies for manufacturing, the following Section 1.3 will clearly outline the contribution of this paper.

\begin{tabular}{|c|c|}
\hline \multicolumn{2}{|c|}{ Supporting tools and methods } \\
\hline Modelling and analysis & Energy assessment tools and methods \\
\hline Simulation of energy consumption characteristics & Energy audits \\
\hline Electricity demand resnonse & Enegry studies and metering \\
\hline & Energy value stream mapping \\
\hline Energy efficiency optimization measures & $6 \sigma$ analysis to decrease Energy Waste and Variation \\
\hline Emission calculation and sustainability tools & Energy saving measures \\
\hline Life cycle assesment & Benchmarking tools and techniques \\
\hline Optimization of emmision values & Best practice analysis \\
\hline Carbon footprint reduction & Energy benchmarking \\
\hline
\end{tabular}

Figure 1. Supporting tools and methods to support energy management in manufacturing as identified from current literature (May et al., 2017).

\subsection{Derivation of Research Demand}

Based on the literature presented in the preceding sections, the following key points are identified.

1. When considering manufacturing facilities as holistic systems that are comprised of the manufacturing processes and the factory building, allows for identifying greater opportunities for resource recovery. 
2. Modelling resource flows in terms of exergy has the benefits of (i) energy quality is considered in addition to its quantity; (ii) resource flows other than energy can be modelled on a common unit basis, thus allowing for identifying greater resource recovery opportunities.

3. The use of exergy analysis for energy and resource management is widespread in academic literature, however its use in the industry is limited. This may be due to lack of acceptance of the exergy concept in the industry and the lack of consistent application in practice.

4. Tools and methods pertaining to energy management can benefit from including non-energy based flows in the analyses [28].

For the reasons that have been summarized above, it would be logical to make efforts to incorporate the exergy concept within energy management standards. However, in very few articles, some authors have either suggested or have attempted to develop such standards. Based on a review of literature and a case study of a building's HVAC system, Karakasli et al. [39], suggested the conversion of energy management standards, such as the ISO 50001, to exergy management standards. Hepbasli [40] proposed an exergy management standard and conducted a case study of a university building. However, some important concepts, such the need for holistic analysis were not recorded. To the best of the author's knowledge, these are the only attempts in literature to incorporate the exergy concept in the energy management standards. Therefore, the prescriptive guidelines that are presented in this paper, in the ISO 50001 format, together with a practical example illustration, would be a step forward in this direction.

\section{Methods}

From the preceding sections, it has been identified that incorporating the exergy concept into an energy management standard may lead to improved energy and resource management in manufacturing. For this purpose, Section 3 provides the exergy based resource management methodology in the form of prescriptive guidelines in an ISO 50001 format. Section 4 illustrates the use of this methodology through a case study of a biscuit manufacturing facility. The factory building is modelled using conventional physical based approach for energy modelling in the built environment [41]. On the other hand, the manufacturing processes are data driven, and their performance is represented using historical metered data. Similar approaches have previously been used to model the material and energy flows in production as they allow the rapidly modelling complex, changing manufacturing systems [42]. Where metered data was not available, a 'rough cut' approach was used to fill the missing gaps. This approach utilized monthly utility bills, operational profiles of the production machines and equipment characterization data to approximate time series energy data. Since the overall simulation approach combined physics based modelling and data driven approaches, the overall modelling methodology that was employed in this study can be termed as a hybrid simulation approach. Data about the manufacturing facility was acquired as part of the project REEMAIN [43]. There are two main objectives of Section 4; (i) To illustrate application of the energy and resource management methodology proposed in this paper; and, (ii) To demonstrate the impact of using exergy analysis on decision making for the selection of technologies towards reduction in resource use.

\section{Towards Improved Industrial Energy and Resource Management}

The methodology that is presented in this section is in a format that supports implementation in practice, as a guide that may facilitate industrial day-to-day operation. It should complement other energy efficiency related standards such as ISO 50000 series. Application of this methodology is relevant to any operational context in which resource efficiency is important. It is likely to be applicable to operations that involve transformations of material, energy, and water resources, such as agriculture, manufacturing, facilities management, and water treatment. On the other hand, it is not likely to be applicable to retail, financial services, or education as they involve intangible flows, such as economic 
value, knowledge or information, etc. In order to achieve energy and resource efficient systems, it is insufficient to implement a linear approach where some efficiency measure is implemented which results in energy savings, without continual feedback for improvement. The methodology that is proposed in this paper is based on the continual improvement framework, Plan-Do-Check-Act (PDCA), to allow for manufacturing facilities to incorporate improved resource efficiency in their daily practice. Figure 2 provides its pictorial description, followed by a listing of the prescriptive guidelines.

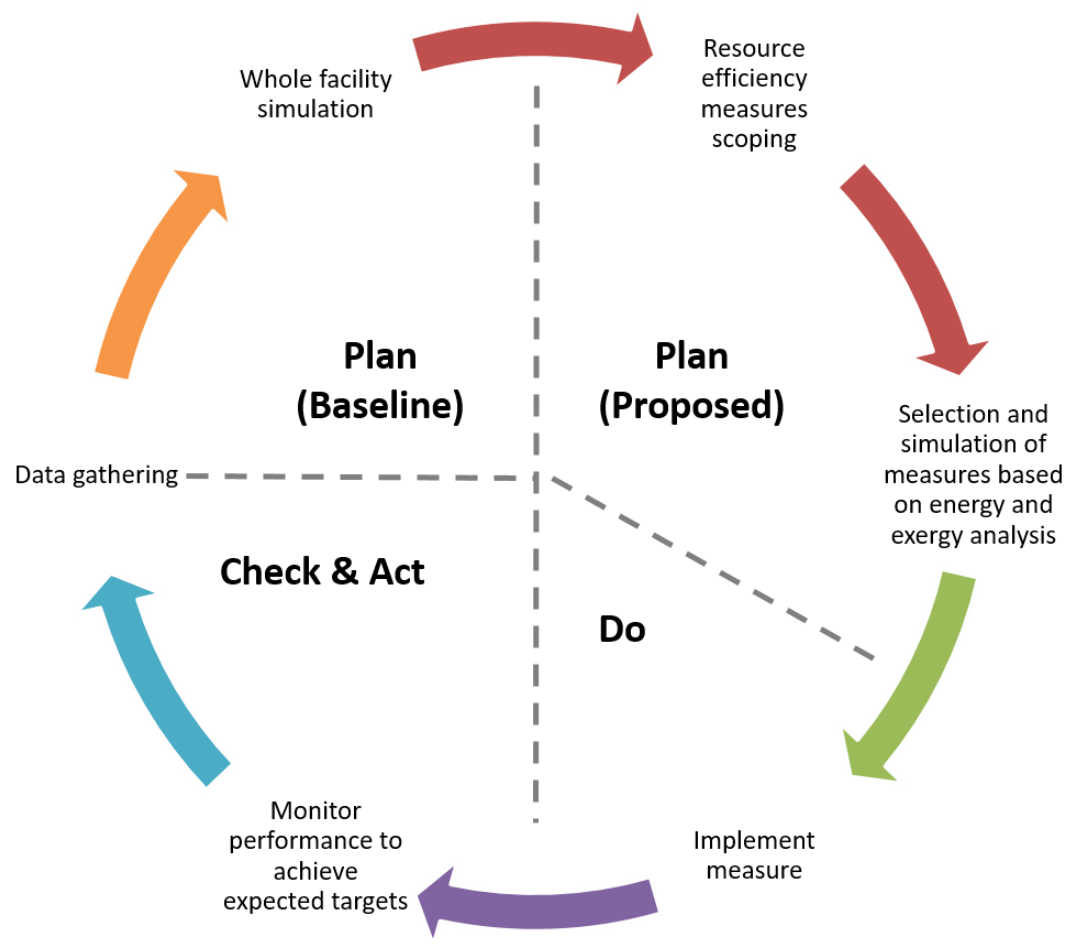

Figure 2. Methodology for improved resource efficient manufacturing.

\subsection{Scope and Boundaries}

Selection of analysis boundaries is an important first step in implementing any efficiency analysis methodology. Expanding system boundaries leads to a more holistic analysis that is better representative of reality, which prevents problem shifting and allows for the identification of a greater number of improvement opportunities. However, doing so is associated with problems of data availability, reliability, and issues of practical implementation. The focus here is the manufacturing facility and therefore the physical and analysis boundaries are defined as such. The decision making resulting from implementing this methodology lies with the manufacturing facility management.

\subsubsection{Physical Boundaries}

- A physical boundary is drawn in line with a gate-to-gate analysis. For a production facility, the factory building is the physical boundary.

\subsubsection{Analysis Scope}

- The analysis scope depends on the factory flows modelling method and analysis type.

- The analysis must incorporate a holistic view of the factory, while taking into considering the interaction between the production equipment and factory building.

- This methodology is designed to be applied to a broad range of industries, energy intensive and non-energy intensive alike, as resource flows includes material and water as well. 
While the analysis boundary may be around a single component in a factory, its performance assessment is based on a whole systems simulation approach. This means that, even though the analysis may be for a single component in the factory, its interaction with other components and the factory building is taken into account through the whole systems simulation approach.

\subsection{Planning for Improved Resource Efficiency}

\section{Data Collection}

- Data about the manufacturing system, factory building, production equipment, and production schedule is acquired.

For manufacturing facilities, there is a large amount of data that needs to be collected. For a factory building, data will be regarding the building geometry, construction, HVAC systems, and operation. For the production, it will be energy consumption data, equipment related information that includes its technical specifications as well as operation schedule. In such a case, it is likely that parts of the data will not be available for which appropriate techniques need to be used. A list of data collection methods that may be used are provided below,

- Acquisition of data through BMS (Building Management Systems) or SCADA (Supervisory Control and Data Acquisition) system.

- Installation of data collection equipment (sensors).

- Application of rough-cut methodology to fill missing gaps in data.

\subsection{Baseline}

- The baseline resource consumption of the manufacturing system is established by modelling and simulation.

- The resource flows in the facility are mapped and visualized based on either energy or material basis, generating Sankey diagrams.

The model must be generated by usage of a software tool that allows for dynamic energy simulation of the factory that takes into account temporal variations, to be validated against actual data.

\section{Identification of Resource Reuse/Recovery Opportunities}

- Based on resource flows visualization, opportunities for resource reuse or consumption minimization are identified.

Following this, suitable technologies and strategies are suggested. System modifications are proposed based on the following six steps/attitudes;

1. Stop: Identify opportunities to stop equipment when not in use,

2. Eliminate: Eliminate unnecessary usage of resources,

3. Repair: If equipment is not operating within its intended parameters, repair it,

4. Reduce: Improve efficiency to reduce resource consumption,

5. Recover: Recover resources by linking factory components (building and production related), and

6. Change: Replace low efficiency components in the factory with high efficiency ones.

The technologies/strategies suitable to address the identified opportunities are to be screened, broadly classified as renewable energy supply (RES), energy storage and waste resource recovery. The initial screening of the identified technologies is to be done using a SWOT (strengths, weaknesses, opportunities, and threats) analysis. The ranking of technologies is to be done by considering four factor groups, technical, economic, marketing, and environmental. The top ranking technologies are then modelled to estimate the payback and resource savings more accurately. 


\subsection{Modelling, Simulation and Analysis of Measures}

- The selected technologies after the screening process are to be simulated to estimate savings in resources.

- A dynamic energy simulation engine is to be used, which allows for modelling the manufacturing facility from a holistic perspective. For a production facility, the factory needs to be modelled as an integrated system of the production processes, the factory building, and building services.

- A suitable method for analyzing the consumption of resources has to be used (such as exergy analysis).

- The predicted performance profile of the selected technologies will serve as 'target desired performance' of the measure.

Based on the simulations and estimated savings, a final list of technologies to be implemented will emerge.

\subsection{Implementation and Operation}

- Physically implement the selected technologies.

- Provide relevant training to personnel to ensure correct operation and maintenance of implemented measure.

- Install appropriate data collection equipment to ensure comparison against simulated desired performance.

\subsection{Monitoring and Correction}

- Monitor the performance of the implemented measure, and to identify solutions to possible issues that impede performing to the desired level.

- Take corrective action at the implemented measure.

3.7. Review and Repeat

- Monitor performance to ensure operation is at targeted desired performance.

- Scope for further opportunities for continual improvement.

\section{Implementation and Findings: Case Study}

A large biscuit manufacturing facility is studied to illustrate application of the methodology presented in the previous section. The biscuit company has a production in excess of 100 tons per year, with a total useful covered area of $87,410 \mathrm{~m}^{2}$. Implementation of the step-by-step methodology is now presented.

\subsection{Physical Boundaries}

The factory building (gate to gate) is selected as the physical analysis boundary.

\subsection{Analysis Scope}

The analysis methods used are energy and exergy analysis, where the system boundary was selected according to the objectives of the specific task. To gain an understanding of the overall resource use in the factory, the whole factory is analyzed, however, in the case of a sub-system, the analysis boundary is sub-system chosen suitably. 


\subsection{Planning for Improved Resource Efficiency}

\subsubsection{Data Collection}

Data collection was done through factory audits, essentially analyzing an investigating the facility to gather the relevant data [44]. Subject to the availability of coarse level data (annual or monthly energy consumption at process/department/factory level), rough cut data profiles were generated from either standardized profiles, adjusted profiles by experienced users, or questionnaires. Other information gathering from the site included; detailed information about production processes, factory building construction materials, and production schedules.

\subsubsection{Baseline}

Based on the collected information, a detailed description of production processes was formed. The modelling and simulation of the baseline scenario for the biscuit factory was carried out using IES-VE [43]. The model of the factory can be seen in Figure 3 where the manufacturing processes are modelled within the factory building, which are visible through the wireframe display. The factory building was modelled using a typical building physics based energy modelling approach [45]. Modelling of production processes in the tool was done through a data driven approach (actual and rough-cut data). This modelling methodology follows a hybrid approach as described previously in Section 2.

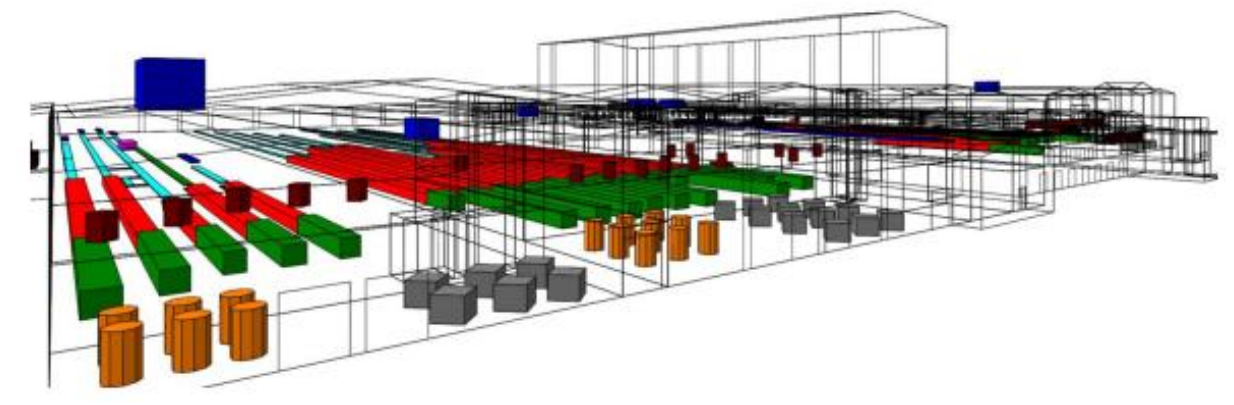

Figure 3. Whole factory model of the biscuit factory.

\subsubsection{Identification of Resource Reuse/Recovery Opportunities}

Through modelling of the factory building, and within it the production processes, a dynamic simulation was carried out thus implementing holistic modelling and analysis at the factory level. This approach resulted in the visualization of factory level energy flows, which are displayed in Sankey diagram format. The factory level Sankey provided a visual that aids in deciding where the major efforts should be directed. Upon inspection of the factory level energy flows, ovens and the chilling systems represented the most significant source of energy consumption. Therefore, any improvements to efficiency in the oven and the cooling systems would impact the factory resource consumption positively. The immediate action would be to consider energy recovery options for the waste heat to reduce natural gas consumption. However, the added objective of this section is to demonstrate the advantage of considering exergy analysis alongside energy analysis, to provide clearer information to inform decision making. For this purpose, the energy flows of a sub-section of the factory were visualized. The Sankey diagram resulting from considering only the electricity that was used at the facility level was generated (Figure 4).

From an inspection of Figure 4, it can be seen that the chillers (cooling lines) use the major portion of electricity used at the facility level. Furthermore, the chiller for cooling line 5 was the largest energy consumer of electricity toward which further efforts needed to be directed. 


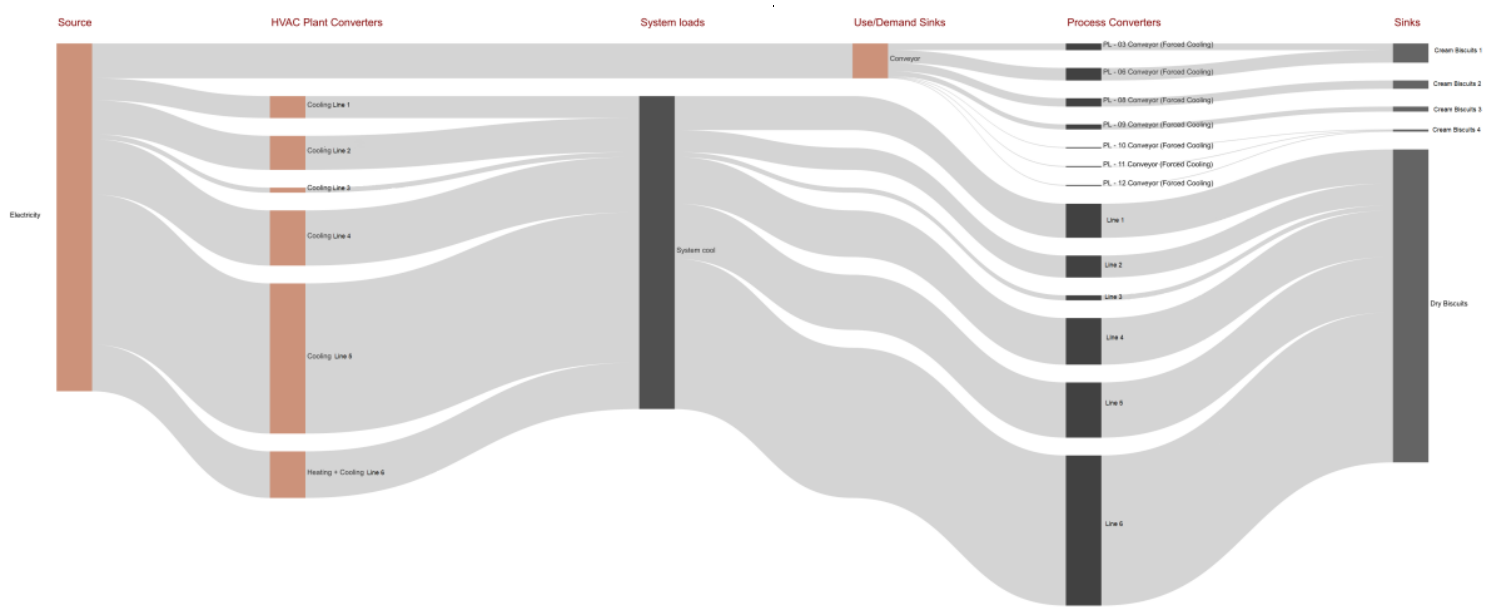

Figure 4. Energy Sankey depicting the use of electricity at factory level.

\subsubsection{Modelling, Simulation and Analysis of Measures}

For electricity that is used at factory level, it was found that efficiency improvement measures needed to be directed towards cooling line 5 . When considering the cold average ambient air temperature conditions at the factory location $\left(5.5^{\circ} \mathrm{C}\right.$ based on historical data), and the required temperature of the chilled water $\left(5^{\circ} \mathrm{C}\right)$, the electrical energy consumption of the chillers could be reduced somehow by utilizing the outdoor weather conditions. A dry cooler was the selected technology as it was expected to be feasible in the technological, economic, and environmental aspects. Figure 5 shows the baseline and the proposed chilling system, as modelled in IES-VE. The proposed modified chilling system employs an external heat exchanger in the return water flow coming from the thermal load. Therefore, the supply water $\left(\right.$ at $\left.10^{\circ} \mathrm{C}\right)$ that reaches the electric chiller does so at a lower temperature in comparison with the baseline. This expected to reduce the thermal load on the chiller.
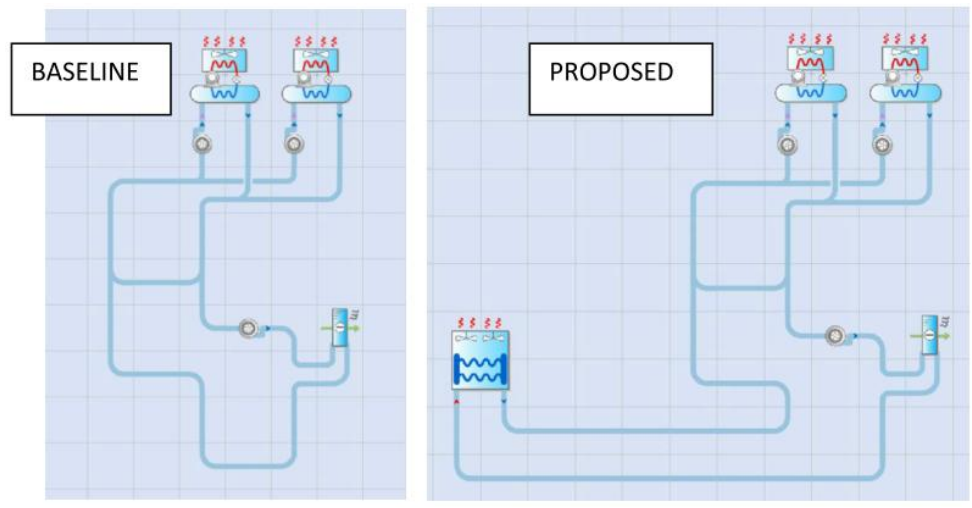

Figure 5. Modelling of the baseline and proposed scenario for cooling line 5 in IES-VE.

Next, the efficiency of the system is assessed using energy and exergy analysis. First, the performance indicators are defined, followed by results that were generated through computer simulation. The supplied input to the system is electricity to the electric chillers, while the useful output of the system is the thermal energy that was extracted from the water supply to cool it to $5^{\circ} \mathrm{C}$. Therefore, the energy efficiency ratio (EER), adjusted for standard international units, of the system is defined as follows [46],

$$
E E R_{\text {cooling system }}=\frac{\text { Rate of heat removal from water to deliver at } 5^{\circ} \mathrm{C}}{\text { Electrical power requirements of the system }}=\frac{\dot{m} c_{p} \Delta T}{E l e c_{\text {demand }}}
$$


The exergy efficiency $\left(\eta_{E x}\right)$ of a system in general is defined as follows [47],

$$
\eta_{E x}=\frac{\text { Useful output exergy }}{\text { Supplied input exergy }}
$$

For the case of the chilling system, the useful output is the heat lost or extracted from the water flow in the chilling circuit. In order to define the useful output exergy, consider a simple pipe through which water flows, and it is cooled by losing heat to the surrounding that are at a lower temperature (Figure 6). Since the chemical composition of the water flow remains the same and no significant pressure variations are expected, only the thermal exergy content of the mass flow needs to be considered.

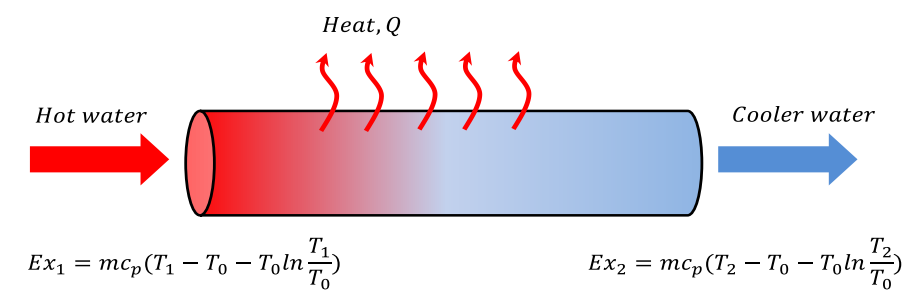

Figure 6. Exergy destruction due to heat loss from a fluid flowing in a simple pipe.

The heat transfer through the pipe wall is an irreversible process and it directly translates into irrecoverable exergy destruction. For the simple pipe shown above, the exergy destruction due to heat loss is then calculated as follows,

$$
E x_{\text {dest from heat flow }}=m c_{p}\left(T_{1}-T_{2}-T_{0} \ln \frac{T_{1}}{T_{0}}+T_{0} \ln \frac{T_{2}}{T_{0}}\right)
$$

For the case of the chilling system, it is this exergy destruction that is the useful output of the system, and therefore the exergy efficiency for the chilling system is defined as,

$$
\eta_{\text {Ex, chilling system }}=\frac{m c_{p}\left(T_{1}-T_{2}-T_{0} \ln \frac{T_{1}}{T_{0}}+T_{0} \ln \frac{T_{2}}{T_{0}}\right)}{\text { Elec }_{\text {demand }}}
$$

A week in January was taken as the analysis period to assess the predicted performance of the baseline and proposed system based on the energy and exergy approaches. The exergy efficiency profile for the baseline and the proposed system can be seen in Figure 7. Table 1 provides the results obtained from the analysis.

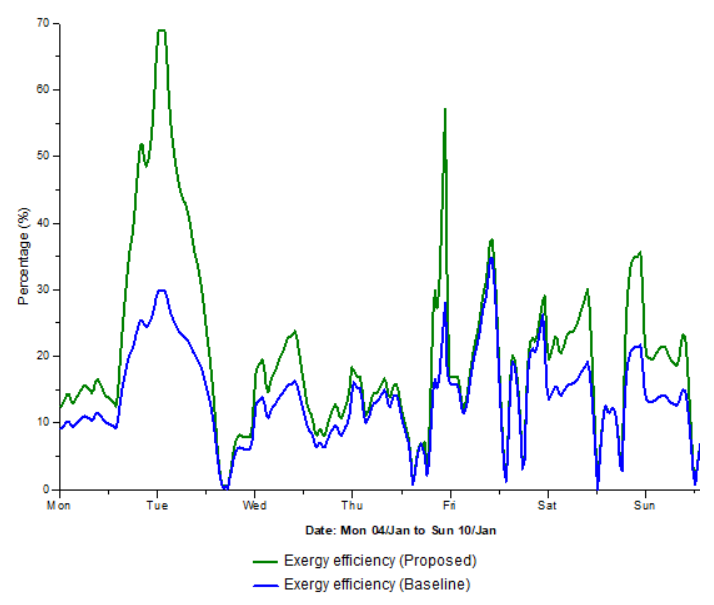

Figure 7. Performance comparison of the baseline and the proposed scenario based on exergy analysis. 
Table 1. The results of the energy and exergy analysis for the baseline and the proposed case for cooling line 5 (Based on a week's data in January).

\begin{tabular}{cccc}
\hline Scenario & Baseline (\%) & Proposed (\%) & Improvement over Baseline (\%) \\
\hline Mean Energy Efficiency Ratio & 14.11 & 17.73 & 25.7 \\
Mean Exergy Efficiency & 13.94 & 20.42 & 46.5 \\
\hline
\end{tabular}

\subsection{Implementation and Operation}

Based on the analysis that was conducted, decisions relating to the implementation of the selected technology were to be taken. Within the REEMAIN project, on which this analysis is based, the proposed modification was accepted. The modification to the system was an external heat exchanger in the return water loop. The heat exchanger was placed on top of the factory roof, above the technical room where the chillers were located. A bypass valve was installed in this new connection for the case where outside temperature did not allow for free cooling. To match this modification, the control strategy of the system was also modified accordingly.

\subsection{Monitoring and Correction}

The modified system was installed together with its required instrumentation and amendments in control systems. In order to identify any problems in the commissioning of the efficiency measure, the system needed to be monitored. The performance of the new system was compared to the targeted performance as set by the simulation results. Measurements over the first ten months showed below par performance. The reasons for this were wrong positioning of a temperature sensor, and a malfunctioning of the modified control systems. As the performance was monitored, the faults were detected and removed accordingly.

\subsection{Review and Repeat}

The performance of the implemented measures is to be monitored continuously to ensure operation at targeted desired level. In addition, scoping for further opportunities for the continual improvement in the factories is to be carried out in the future.

\section{Conclusions}

In this paper, prescriptive guidelines for energy management in the format of the ISO 50001 were presented. The presentation was done through an illustrative case study of a biscuit manufacturing facility. The factory level Sankey diagram of the energy flows indicated that natural gas consumption and electricity consumption in the baking and the chilling lines were the greatest energy consumers. For the purposes of demonstrating the utility of exergy analysis in generating clearer information to support decision making for energy management, the largest electricity consuming chilling line 5 was further explored. Since the required water temperature was $5{ }^{\circ} \mathrm{C}$, and when considering the cold local climate, a dry fan cooler was proposed as an appropriate efficiency measure. The baseline and the proposed case were modelled holistically and simulated using IES-VE, with the results being tabulated in Table 1.

The mean energy efficiency ratio improved from 14.11 to 17.73 for the baseline and proposed systems, respectively, which is an improvement of $25.7 \%$ over the baseline performance. On the other hand, the exergy efficiency improved from only 13.94 to $20.42 \%$ over the same period of analysis, an improvement of $46.5 \%$ over the baseline. Comparing the energy and exergy based results, a drawback with the energy efficiency ratio is that there is no indication of how much further improvement is possible, as a theoretical ideal reference is not defined. For the exergy results, even though a greater improvement over the baseline was recorded $(46.5 \%)$, the proposed case is still highly exergy-inefficient, with a theoretical $79.27 \%$ further improvement being possible. Such a difference in results that was produced by the energy and exergy analyses may lead the decision makers 
of the factory energy management in different directions. The marked difference in results is due to the fact that an energy analysis disregards the quality aspects of energy. For example, the same quantity of a thermal energy in water at $5{ }^{\circ} \mathrm{C}$ and electrical energy are considered to be equal, even though more useful work is possible with the electrical energy. Furthermore, exergy is a property of the system and the surrounding (in this case the outside natural environment) and represents variation from the reference environment. When considering that the local climate is close to the required water temperature $\left(5^{\circ} \mathrm{C}\right)$ for a significant amount of time, very little exergy is imparted to the water flow. On the other hand, on the supply side, high quality energy (electricity) is used. This mismatch between the high energy quality at the supply and low energy quality at the demand side in the cooling system leads to low exergy efficiency values.

Although, this example provided a case to demonstrate the added insight that could be achieved through employing the exergy approach, it was not the primary objective of this paper. Rather, the main contribution of this paper is to present a set of prescriptive guidelines, in the ISO 50001 standard format, which incorporate the useful concept of exergy and is based on holistic simulation of factories. The generic guidelines presented in Section 3 can be considered to be a step towards an exergy based energy management standard to deliver improved energy and efficiency in the industry.

The holistic factory simulation software tool that is presented in this paper was restricted to the generation of Sankey diagrams of energy and material flows. The exergy based methodology that is presented may be readily expanded to take into account water flows in addition to energy and material, thus expanding the scope to resource management in factories (as suggested by recent literature [28]). Future work may be directed towards expanding the capability of such tools to generate Grassmann diagrams to visualize all of the resource flows on a common unit basis. Such a development would further aid the holistic analysis of manufacturing systems and decision making for resource efficiency. Finally, the adoption of technologies and techniques is not entirely dependent on technical analysis and results. Non-technical factors, such as the common perception about the tools, are equally important. To date, there is still scant literature on the barriers and drivers to the widespread use of exergy analysis in the industry. Perhaps investigations along such lines merit further research to uncover the reasons that impeded improved energy and resource management in factories through the greater use of exergy analysis.

Acknowledgments: This work was supported by the project REEMAIN (Resource and Energy Efficient Manufacturing). It received funding from the European Union's Seventh Programme for research, technological development and demonstration under grant agreement No. 608977. The authors would like to thank Vincent Murray and Stephen Earl for their contribution towards development of the computer models used.

Author Contributions: Sanober Hassan Khattak designed the study, conducted the analysis and is the main author of the paper. Michael Oates developed the computer models used in the study. Rick Greenough provided critical feedback on the design of the study.

Conflicts of Interest: The authors declare no conflict of interest.

\section{References}

1. Administration, E.I. Industrial Sector Energy Consumption—International Energy Outlook; U.S. Energy Information Administration: Washington, DC, USA, 2016.

2. European Commission. A Resource-Efficient Europe-Flagship Initiative under the Europe 2020 Strategy; European Commission: Brussels, Belgium, 2011; Volume 21, pp. 1-17.

3. Kaźmierczyk, P.; Stenbaek Hansen, M.; Günther, J.; McKinnon, D.; Loewe, C.; Lingvall, F.; Kallay, T.K.; Szlezak, J.; Bahn-Walkowiak, B.; Herczeg, M. Resource Efficiency in Europe: Policies and Approaches in 31 EEA Member and Cooperating Countries; European Environment Agency: Copenhagen, Denmark, 2012.

4. Dawkins, E.; Roelich, K.; Barrett, J.; Baiocchi, G. Securing the Future-The Role of Resource Efficiency; WRAP: Banbury, UK, 2010.

5. Herrmann, C.; Thiede, S.; Heinemann, T. A Holistic Framework for Increasing Energy and Resource Efficiency in Manufacturing; Springer: Berlin/Heidelberg, Germany, 2011; pp. 3-4. 
6. Wright, A.J.; Oates, M.R.; Greenough, R. Concepts for dynamic modelling of energy-related flows in manufacturing. Appl. Energy 2013, 112, 1342-1348. [CrossRef]

7. Ball, P.D.; Despeisse, M.; Evans, S.; Greenough, R.M.; Hope, S.B.; Kerrigan, R.; Levers, A.; Lunt, P.; Murray, V.; Oates, M.R.; et al. Factory modelling: Combining energy modelling for buildings and production systems. IFIP Adv. Inf. Commun. Technol. 2013, 397, 158-165.

8. Duflou, J.R.; Sutherland, J.W.; Dornfeld, D.; Herrmann, C.; Jeswiet, J.; Kara, S.; Hauschild, M.; Kellens, K. Towards energy and resource efficient manufacturing: A processes and systems approach. CIRP Ann. Technol. 2012, 61, 587-609. [CrossRef]

9. Herrmann, C.; Schmidt, C.; Kurle, D.; Blume, S.; Thiede, S. Sustainability in manufacturing and factories of the future. Int. J. Precis. Eng. Manuf. Green Technol. 2014, 1, 283-292. [CrossRef]

10. Cerdas, F.; Kurle, D.; Andrew, S.; Thiede, S.; Herrmann, C.; Zhiquan, Y.; Jonathan, L.S.C.; Bin, S.; Kara, S. Defining circulation factories-A pathway towards factories of the future. Procedia CIRP 2015, 29, 627-632. [CrossRef]

11. Kovacic, I.; Orehounig, K.; Mahdavi, A.; Bleicher, F.; Dimitrou, A.-A.; Waltenbereger, L. Energy Efficient Production-Interdisciplinary, Systemic Approach through Integrated Simulation. Stroj. J. Theory Appl. Mech. Eng. 2013, 55, 17-34.

12. Caggiano, A.; Marzano, A.; Teti, R.; Design, S. Sustainability Enhancement of a Turbine Vane Manufacturing Cell through Digital Simulation Based Design. Energies 2016, 9, 790. [CrossRef]

13. Garwood, T.L.; Hughes, B.R.; Oates, M.R.; Connor, D.O. A review of energy simulation tools for the manufacturing sector. Renew. Sustain. Energy Rev. 2018, 81, 895-911. [CrossRef]

14. Sousa, T.; Brockway, P.E.; Cullen, J.M.; Miller, J.; Cabrera, A.; Domingos, T. The Need for Robust, Consistent Methods in Societal Exergy Accounting. Ecol. Econ. 2017, 141, 11-21. [CrossRef]

15. Hernandez, A.G.; Cullen, J.M. Unlocking Plant-level Resource Efficiency Options: A Unified Exergy Measure. Procedia CIRP 2016, 48, 122-127. [CrossRef]

16. Mousavi, S.; Kara, S.; Kornfeld, B. A hierarchical framework for concurrent assessment of energy and water efficiency in manufacturing systems. J. Clean. Prod. 2016, 133, 88-98. [CrossRef]

17. Thiede, S.; Schönemann, M.; Kurle, D.; Herrmann, C. Multi-level simulation in manufacturing companies: The water-energy nexus case. J. Clean. Prod. 2016, 139, 1118-1127. [CrossRef]

18. Khattak, S.H.; Greenough, R. Resource Accounting in Factories and the Energy-Water Nexus; Springer: New York, NY, USA, 2017.

19. Khattak, S.H.; Greenough, R. Resource efficient manufacturing: Can reduced energy efficiency lead to improved sustainability? ECEE Ind. Summer Study Proc. 2014, 163-169. Available online: www.eceee.org (accessed on 2 March 2018).

20. Khattak, S.H.; Greenough, R.; Korolija, I.; Brown, N. An exergy based approach to resource accounting for factories. J. Clean. Prod. 2016, 121, 99-108. [CrossRef]

21. Wall, G. Exergy flows in industrial processes. Energy 1988, 13, 197-208. [CrossRef]

22. Atmaca, A.; Yumrutaş, R. Thermodynamic and exergoeconomic analysis of a cement plant: Part I-Methodology. Energy Convers. Manag. 2014, 79, 790-798. [CrossRef]

23. McKenna, R. Industrial Energy Efficiency: Interdisciplinary Perspectives on the Thermodynamic, Technical and Economic Constraints; University of Bath: Bath, UK, 2009.

24. Gaudreau, K.; Fraser, R.A.; Murphy, S. The characteristics of the exergy reference environment and its implications for sustainability-based decision-making. Energies 2012, 5, 2197-2213. [CrossRef]

25. Rosen, M.A. Does industry embrace exergy? Exergy Int. J. 2002, 2, 221-223. [CrossRef]

26. Khattak, S.H. An Exergy Based Method for Resource Accounting in Factories. Ph.D. Thesis, De Montfort University, Leicester, UK, January 2016.

27. Sangi, R.; Müller, D. Implementation of a solution to the problem of reference environment in the exergy evaluation of building energy systems. Energy 2018, 149, 830-836. [CrossRef]

28. May, G.; Stahl, B.; Taisch, M.; Kiritsis, D. Energy management in manufacturing: From literature review to a conceptual framework. J. Clean. Prod. 2017, 167, 1464-1489. [CrossRef]

29. Johansson, M.T.; Thollander, P. A review of barriers to and driving forces for improved energy efficiency in Swedish industry-Recommendations for successful in-house energy management. Renew. Sustain. Energy Rev. 2018, 82, 618-628. [CrossRef] 
30. Iker, L.; Ander, I.; Allur, A.; Larrea, E. Contribution to Energy Management of the Main Standards for Environmental Management Systems. Energies 2017, 10, 1758. [CrossRef]

31. A Management System for Energy. ANSI/MSE 2000:2008. Available online: https://webstore.ansi.org (accessed on 10 March 2018).

32. Dzene, I.; Polikarpova, I.; Zogla, L.; Rosa, M. Application of ISO 50001 for implementation of sustainable energy action plans. Energy Procedia 2015, 72, 111-118. [CrossRef]

33. Standardization, I.O. The ISO Survey of Management System Standard Certifications 2016. Available online: https: / / www.iso.org/the-iso-survey.html (accessed on 10 March 2018).

34. Bonacina, F.; Corsini, A.; De Propris, L.; Marchegiani, A.; Mori, F. Industrial Energy Management Systems in Italy: State of the art and perspective. Energy Procedia 2015, 82, 562-569. [CrossRef]

35. Gopalakrishnan, B.; Ramamoorthy, K.; Crowe, E.; Chaudhari, S.; Latif, H. A structured approach for facilitating the implementation of ISO 50001 standard in the manufacturing sector. Sustain. Energy Technol. Assess. 2014, 7, 154-165. [CrossRef]

36. Vermeeren, R.; Mulder, B.; Meta, B.V.; Reijnders, M. Implementation of ISO 50001 in Industry in the Netherlands. ECEE Ind. Summer Study Proc. 2012, 679-688. Available online: www.eceee.org (accessed on 2 March 2018).

37. Kanneganti, H.; Gopalakrishnan, B.; Crowe, E.; Al-shebeeb, O.; Yelamanchi, T.; Nimbarte, A.; Currie, K.; Abolhassani, A. Speci fi cation of energy assessment methodologies to satisfy ISO 50001 energy management standard. Sustain. Energy Technol. Assess. 2017, 23, 121-135.

38. Jovanovi, B.; Filipovi, J. ISO 50001 standard-based energy management maturity model e proposal and validation in industry. J. Clean. Prod. 2016, 112, 2744-2755. [CrossRef]

39. Karakasli, E.; Oztop, H.; Hepbasli, A. Performance assessment of a polyclinic heating and cooling system in a hospital building. Int. J. Exergy 2016, 21, 70-86. [CrossRef]

40. Hepbasli, A. Towards Developing An Exergy Management System Standard and Its Application to a University Building. In CLIMA 2016_Proceedings of the 12th REHVA World Congress; Aalborg University, Department of Civil Engineering: Aalborg, Denmark, 2016.

41. Nguyen, A.; Reiter, S.; Rigo, P. A review on simulation-based optimization methods applied to building performance analysis. Appl. Energy 2014, 113, 1043-1058. [CrossRef]

42. Wang, J.; Chang, Q.; Xiao, G.; Wang, N.; Li, S. Data driven production modeling and simulation of complex automobile general assembly plant. Comput. Ind. 2011, 62, 765-775. [CrossRef]

43. Resource and Energy Efficient Manufacturing. Available online: http://www.reemain.eu/ (accessed on 12 March 2018).

44. CETIAT Energy Performance Diagnosis: The Key to Improve Your Performance. Available online: http:/ / industrie.cetiat.fr/gb / p-gb/energy-performance-diagnosis-the-key-to-improve-your-performance.html (accessed on 4 April 2018).

45. Harish, V.S.; Kumar, A. A review on modeling and simulation of building energy systems. Renew. Sustain. Energy Rev. 2016, 56, 1272-1292. [CrossRef]

46. Air-conditioning, heating and refrigeration institute. AHRI 550/590 (I-P/2015): Performance Rating of Water-Chilling and Heat Pump Water-Heating Packages Using the Vapour Compression Cycle. Available online: https:/ / ahrinet.org/search-standards (accessed on 15 April 2018).

47. Bakshi, B.R.; Gutowski, T.G.; Sekulic, D.P. Thermodynamics and the Destruction of Resources; Thoughts on the Application of Thermodynamics to the Development of Sustainability Science; Cambridge University Press: Cambridge, UK, 2011; pp. 477-488.

(C) 2018 by the authors. Licensee MDPI, Basel, Switzerland. This article is an open access article distributed under the terms and conditions of the Creative Commons Attribution (CC BY) license (http://creativecommons.org/licenses/by/4.0/). 